\title{
Investigating the Vulnerabilities of Structures to Ignition From a Firebrand Attack
}

\author{
SAMUEL L. MANZELLO ${ }^{1}$, JOHN R. SHIELDS ${ }^{1}$, YOSHIHIKO HAYASHI ${ }^{2}$, and DAISAKU NII ${ }^{2}$ \\ ${ }^{1}$ Building and Fire Research Laboratory (BFRL) \\ National Institute of Standards and Technology (NIST) \\ 100 Bureau Drive, Gaithersburg, MD 20899-8662 USA \\ ${ }^{2}$ Department of Fire Engineering \\ Building Research Institute (BRI) \\ 1 Tachihara, Tsukuba, Ibaraki, 305-802 Japan
}

\begin{abstract}
A unique experimental apparatus, known as the Firebrand Generator, was used to generate a controlled and repeatable size and mass distribution of glowing firebrands. The size and mass distribution of firebrands produced from the generator was selected to be representative of firebrands produced from burning vegetation. The vulnerability of roofing materials to firebrand attack was ascertained using fluxes of firebrands produced using this device. The experiments were performed at the Fire Research Wind Tunnel Facility (FRWTF) at the Building Research Institute (BRI) in Tsukuba, Japan. A custom mounting assembly was constructed to support full scale sections of common roofing materials inside the FRWTF. The sections constructed for testing included full roofing assemblies (base layer, tar paper, and shingles) as well as only the base layer material, such as oriented strand board (OSB). The custom mounting assembly allowed for the construction of flat roofs as well as the construction of angled roofs (valleys). Results of this study are presented and discussed.
\end{abstract}

KEYWORDS: wildland-urban interface (WUI) fires, ignition, firebrands, roofing

\section{INTRODUCTION}

The Wildland-Urban Interface (WUI) is defined as a location where structures meet or intermingle with undeveloped wildland. In 2003, WUI fires in the vicinity of San Diego, California displaced nearly 100,000 people and destroyed over 3000 homes, leading to over \$2B in insured losses [1]. Most recently, WUI fires that occurred in Southern California in 2007 displaced 500,000 people and destroyed several thousand structures.

Because of the current historic role in wildland fire fighting (not WUI fires), little effort has been spent on improving our understanding of WUI fire behavior. There is a lack of quantitative information on the processes of structure ignition in WUI fires. Anecdotal evidence suggests that firebrands are a major cause of structural ignition in WUI fires. Most of the literature regarding firebrands has been focused on determining how far firebrands will travel [2-11]. Attempting to quantify vulnerabilities that exist on structures to a firebrand attack has not been considered in detail.

In addition to the USA, Japan has been plagued by structural ignition from firebrands. The initial fire outbreak mechanism is different in Japan than the USA. Japan is a country subjected to many earthquakes due to its geographical location. After these earthquakes have occurred, many fires are produced. Traditional ceramic roofing tiles are displaced as a result of the earthquakes exposing the bare wood roof under pining. Firebrands are produced as structures burn and with the presence of high winds these firebrands are dispersed throughout the atmosphere and produce spot fires which result in severe urban fires that are difficult to extinguish.

A desired approach to mitigate firebrand ignition of structures in WUI fires in the USA and urban fires in Japan is to design homes that are more resistant to firebrand ignition. Naturally, building codes and standards are needed to guide construction of new structures in areas known to be prone to these fires. For these building codes and standards to be relevant, a thorough scientific methodology must be developed to understand the types of materials (e.g. roofing and siding materials) that can be ignited by firebrands as 
well as vulnerable points on a structure where firebrands may easily enter (e.g. building vents). Experimental methods are clearly needed to generate a controlled flux of firebrands on a realistic scale and direct this firebrand flux onto components of a structure to ascertain their resistance to ignition as a part of a full scale structural system.

A unique experimental apparatus, known as the Firebrand Generator, has been constructed to generate a controlled and repeatable size and mass distribution of glowing firebrands. Prior ignition testing using the Firebrand Generator considered the penetration of firebrands into building vents [12]. The impetus for this work was the recently adopted WUI California Building Standards intended to mitigate firebrand penetration through building vents; a screen size of $6 \mathrm{~mm}$ was recommended. To our knowledge, this size was not based on scientific testing but rather a best guess. Accordingly, a structure was installed inside the Fire Research Wind Tunnel Facility (FRWTF) at the Building Research Institute (BRI) in Tsukuba, Japan. A gable vent was installed on the front face of the structure and three different steel screens were installed behind a gable vent to ascertain the ability of the screen to block firebrands from penetrating into the structure. Behind the screens, shredded paper of fixed moisture content was placed in pans to observe if the firebrands that penetrated the vent and subsequent screen were able to produce an ignition event. The mechanism of firebrand penetration through screens was observed for the first time. Firebrands were blown through the vent and were pressed against the steel screen. The firebrands were not quenched by the presence of the screen and would continue to burn until they were small enough to fit through the screen opening. For all screen sizes tested, the firebrands were observed to penetrate the screen and produce a self-sustaining smoldering ignition inside the paper beds installed inside the structure. For the $6 \mathrm{~mm}$ screens tested a majority of the firebrands simply flew through the screen, resulting in an ignition of the paper behind the screen considerably more quickly as compared to the smaller screen sizes of $3 \mathrm{~mm}$ and 1.5 mm. The results of these experiments demonstrate the danger of firebrand storms in these fires.

The present study is concerned with investigating the ignition of common roofing materials to a controlled firebrand attack using the Firebrand Generator. While current standards exist to test ignition of roofing to firebrand deposition, such as ASTM E108, these standards simply place a burning wood crib on top of a section of a roof assembly and apply an air flow [13]. The current standards are not capable of testing the dynamic process of multiple firebrands landing on roofing materials as a function of time; this behavior has been documented in real WUI fires as well as urban fires over and over again. As an example of this, many ceramic roofing types are designated as passing the standard since a burning wood crib will not ignite ceramic tile. However, based on post-fire analysis of actual WUI fires, the base roofing layer under ceramic roofs was observed to ignite due to continual bombardment of firebrands below the ceramic tiles.

As a result, a custom mounting assembly was constructed to support full scale sections of common roofing materials inside the FRWTF. The full scale sections constructed for testing included roofing assemblies (base layer, tar paper, and asphalt shingles) as well as only base layer roofing materials, such as oriented strand board (OSB). The custom mounting assembly allowed for the construction of flat roof sections as well as the construction of angled (valleys) roof sections. A housing survey of common roofing designs was completed to guide those used for testing.

\section{EXPERIMENTAL DESCRIPTION}

Figure 1 is a drawing of the experimental apparatus. The present apparatus is a scaled up version of a smaller first generation, proof-of-concept device [14]. The current, scaled up version of the device has been described elsewhere and has been used to investigate the penetration of firebrands into building vents [12]; a brief description of the device is provided here for completeness. The bottom panel displays the procedure for loading the Douglas-Fir tree mulch into the apparatus. The mulch pieces were deposited into the firebrand generator by removing the top portion. The mulch pieces were supported using a stainless steel mesh screen (0.35 cm spacing), which was carefully selected. Two different screens were used to filter the mulch pieces prior to loading into the firebrand generator. The first screen blocked all mulch pieces larger than $25 \mathrm{~mm}$ in diameter. A second screen was then used to remove all needles from the mulch pieces. The justification for this filtering methodology is provided below. A total of $2.1 \mathrm{~kg}$ of mulch was used as the initial mass for each of the experiments. The average moisture content of the mulch pieces used at ignition was $10 \%$ (dry basis). The mulch was produced from $4.0 \mathrm{~m}$ Douglas-Fir trees. The 
firebrand generator was driven by a $1.5 \mathrm{~kW}$ blower that was powered by a gasoline electrical generator. The gasoline electric generator provided the blower with the necessary power requirements (see Fig. 1). These power requirements were not available at the FRWTF, necessitating the use of a portable power source.

\section{Firebrand Generator Assembled \\ Side View}

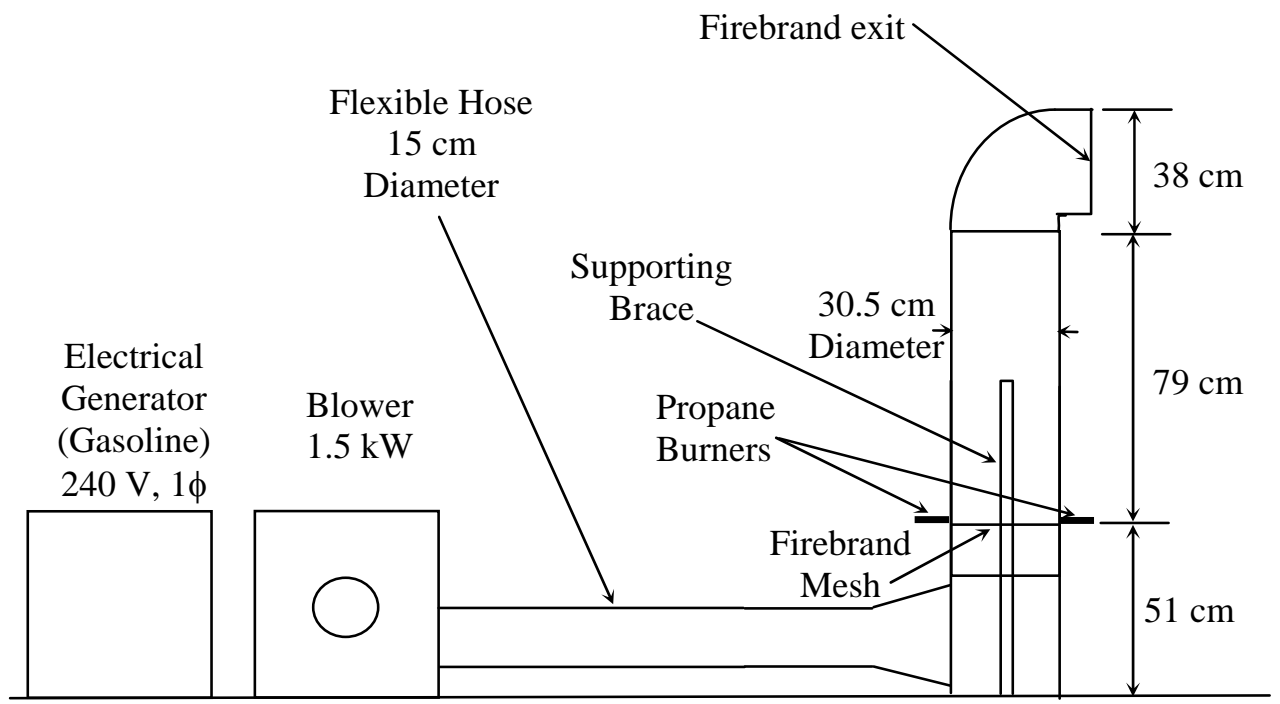

\section{Firebrand Generator Disassembled To Load Firebrands Front View}

Douglas-Fir Mulch Poured Into $2.1 \mathrm{~kg}$ Initial Mass

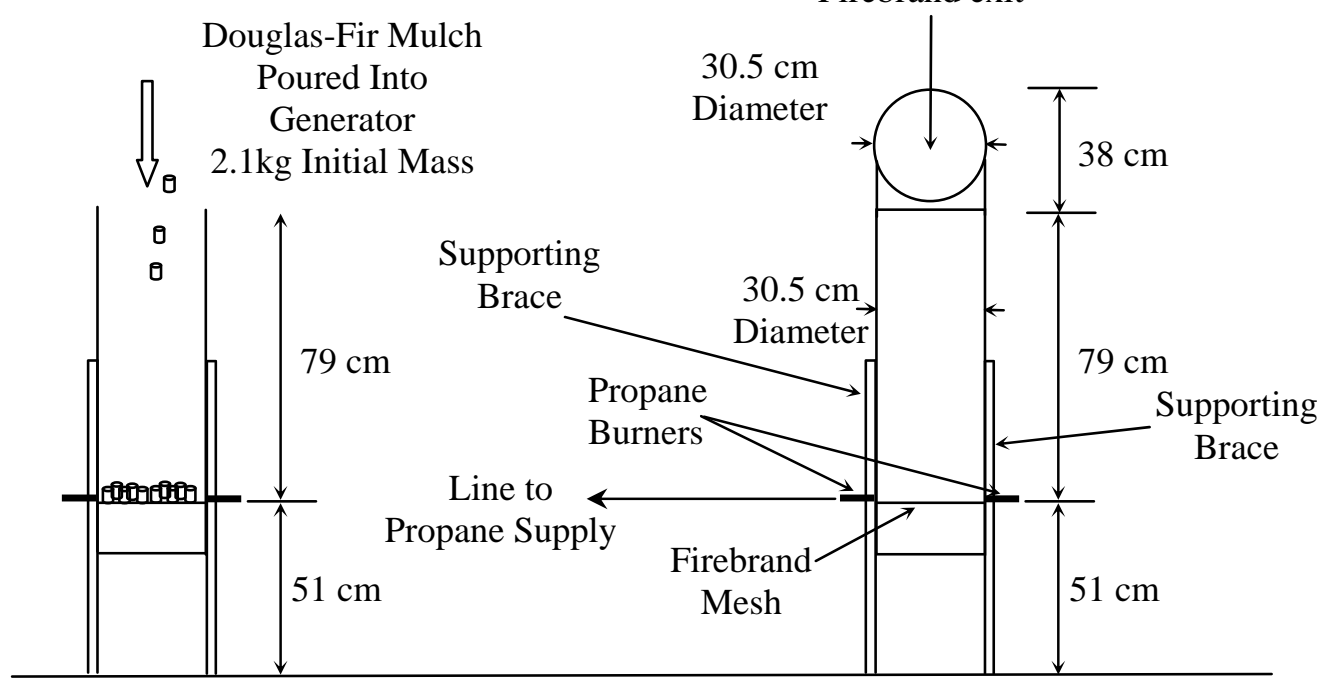

\section{Firebrand Generator Assembled Front View}

Fig. 1. Firebrand Generator - Top Panel shows the device fully constructed while the bottom panel displays the procedure for loading the device.

After the Douglas-Fir tree mulch was loaded, the top section of the firebrand generator was coupled to the main body of the apparatus (see Fig. 1). With the exception of the flexible hose, all components of the 
apparatus were constructed from either galvanized steel or stainless steel (0.8 $\mathrm{mm}$ in thickness). The blower was then switched to provide a low flow for ignition $(1.0 \mathrm{~m} / \mathrm{s}$ flow inside the duct measured upstream of the wood pieces). The two propane burners were then ignited individually and simultaneously inserted into the side of the generator. Each burner was connected to a $0.635 \mathrm{~cm}$ diameter copper tube with the propane regulator pressure set to $344 \mathrm{kPa}$ at the burner inlet; this configuration allowed for a $1.3 \mathrm{~cm}$ flame length from each burner. The Douglas-Fir mulch was ignited for a total time of 45 seconds. After 45 seconds of ignition, the fan speed of the blower was increased $(2.0 \mathrm{~m} / \mathrm{s}$ flow inside the duct measured upstream of the wood pieces). The burners were subsequently switched off at 90 seconds after ignition. This sequence of events was selected in order to generate a continuous flow of glowing firebrands for approximately six minutes duration. The principle behind the operation of the apparatus was rather simple, after ignition, the mulch would begin to burn and the density decreased until which point the low air flow passing through the support mesh was able to loft and exit the device as firebrands at low velocity. The timing and fan blower speed timing is not random; if a higher fan speed of the blower was selected, the firebrands produced would be forced out of the exit earlier, resulting in flaming firebrands, which was not desired.

The Firebrand Generator was installed inside the test section of the FRWTF at BRI. A drawing of the facility is shown in Fig. 2 and displays the location of the firebrand generator with respect to the roofing sections used for ignition testing. The facility was equipped with a $4.0 \mathrm{~m}$ fan used to produce the wind field and was capable of producing up to a $10 \mathrm{~m} / \mathrm{s}$ wind flow. The wind flow velocity distribution was verified using a 21 point hot wire anemometer array. To track the evolution of the size and mass distribution of firebrands produced, a series of water pans was placed downstream of the Firebrand Generator. Details of the size and mass distribution of firebrands produced from the device are presented below.

\section{RESULTS AND DISCUSSION}

In a similar manner to prior work, it was desired to be able to produce firebrands that are characteristic of those produced by burning trees. In prior work characterizing the size and mass distribution of firebrands generated from burning trees, it was observed that the mass distribution of firebrands produced from two different tree species under similar moisture levels and crown size ranges were similar for mass classes up to $0.4 \mathrm{~g}$ [15-16]. A noticeable difference was observed in the larger mass classes. It was also observed that more than $85 \%$ of the firebrands produced from trees were in mass classes up to $0.4 \mathrm{~g}$. Accordingly, the input conditions for the firebrand generator were intentionally selected to produce firebrands with mass classes up to $0.4 \mathrm{~g}$. This was accomplished by sorting the Douglas-Fir tree mulch using a series of filters prior to being loaded into the firebrand generator. The same filtering procedure was used previously when Korean Pine trees were used as the mulch source [12].

The firebrands produced from the Firebrand Generator were captured using an array of water filled pans. The generated firebrands landed in the water filled pans and the presence of water quenched combustion. The firebrands were subsequently removed from the water pans and dried. Since many of the firebrands produced are cylindrical, the length and diameter of the generated firebrands was measured. This information was then used to calculate the surface area of the firebrands produced and was plotted as a function of the measured firebrand mass (see Fig. 3). Figure 3 also displays the same analysis performed for firebrands collected from Douglas-Fir trees as well as Korean Pine Trees under similar moisture content. From the figure, the firebrand generator was capable of producing the size and mass distribution of firebrands from burning trees up to $0.4 \mathrm{~g}$.

After the size and mass distribution of firebrands produced from the Firebrand Generator was determined, a custom mounting assembly was constructed to support full scale sections of common roofing materials inside the wind tunnel. For all the tests conducted, the generator was located $3 \mathrm{~m}$ from the mounting assembly. A schematic of the mounting assembly is shown in Fig. 4. 


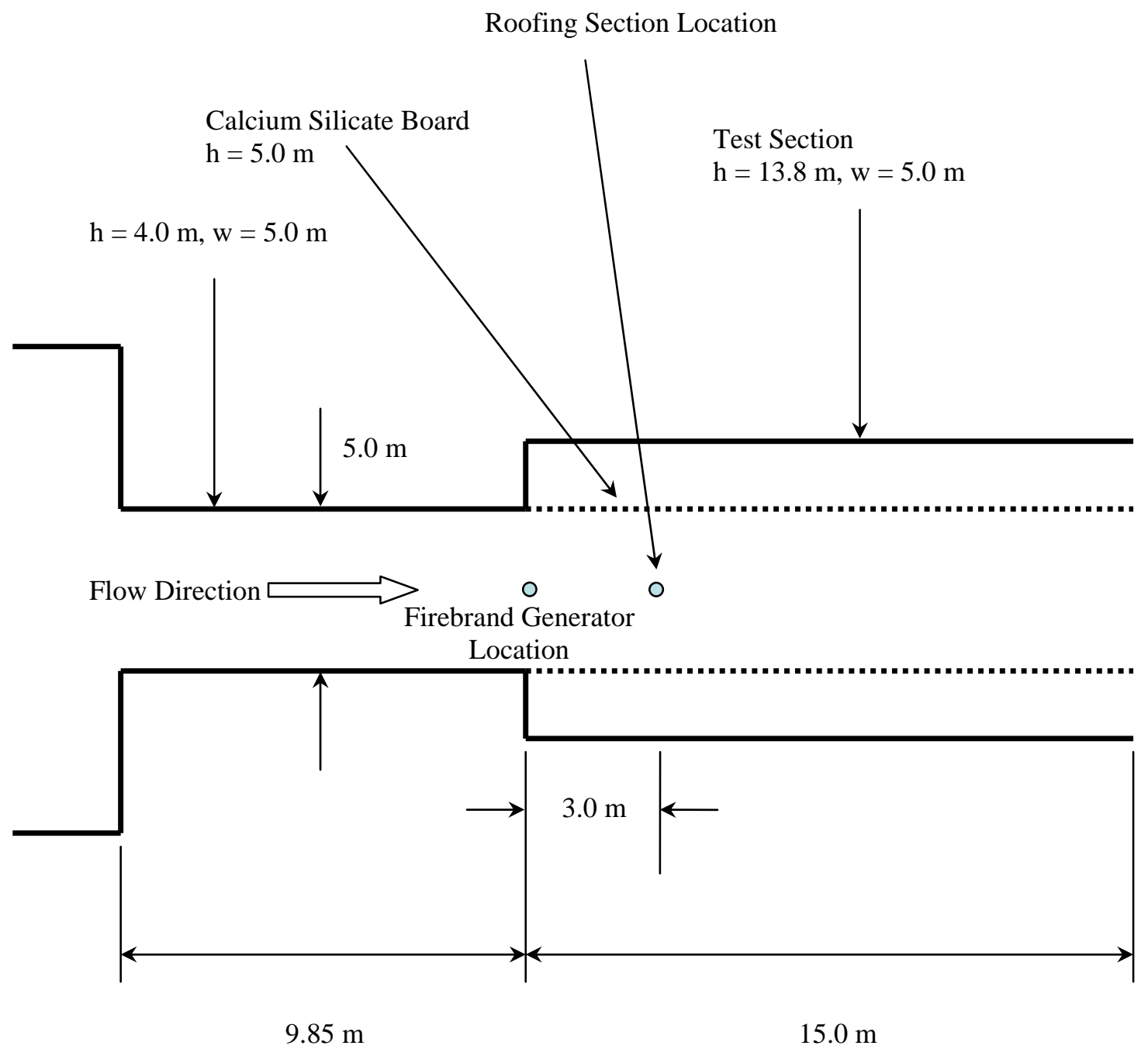

Fig. 2. Schematic of the FRWTF (Top View). The location of the Firebrand Generator with respect to the roofing assemblies is shown.

Prior to conducting the experiments at the FRWTF, small scale experiments were conducted at NIST to determine whether it was possible for glowing firebrands to ignite crevices of building materials used for roof construction. The principal behind the small scale experiments was two fold: (1) to determine the range of conditions under which it is not possible to ignite crevices of base layer roofing materials (OSB), and (2) and verify whether the small scale results would produce similar behavior at full scale. Clearly, the use of small scale experiments to predict full scale behavior would be desired.

In the USA, there has been a dramatic shift to the use of OSB in North America; historically plywood was the dominant materials used in base layer of roofs [17]. The reasons for this are primarily economic in nature. OSB is manufactured from smaller trees as compared to plywood and consists primarily of wood fragments. Further details of the small scale experiments are the subject of another publication; only the results are provided here [18]. The small scale apparatus has been used to investigate ignition of various fuel beds types [19]. The OSB pieces were cut into rectangular sections of $206 \mathrm{~mm}$ by $88 \mathrm{~mm}$ and the fuel bed angle was varied from $60^{\circ}$ to $135^{\circ}$. Glowing firebrands were deposited into the OSB crevices and an air flow was applied; no ignition events were observed over the range of angles tested for applied air flow 
less than $2.4 \mathrm{~m} / \mathrm{s}$. For the tightest fuel bed angle of $60^{\circ}$, the glowing firebrands deposited (total of four) on the fuel bed always resulted in smoldering ignition for OSB. At the fuel bed angle of $90^{\circ}$, no definitive ignition behavior was observed; different ignition criteria (no ignition and smoldering ignition) were observed under identical experimental conditions. As the fuel bed angle was increased up to $135^{\circ}$, ignition never occurred any more for OSB. Based on these ignition results, the critical angle for ignition exists between $90^{\circ}$ and $135^{\circ}$ at a given air flow.

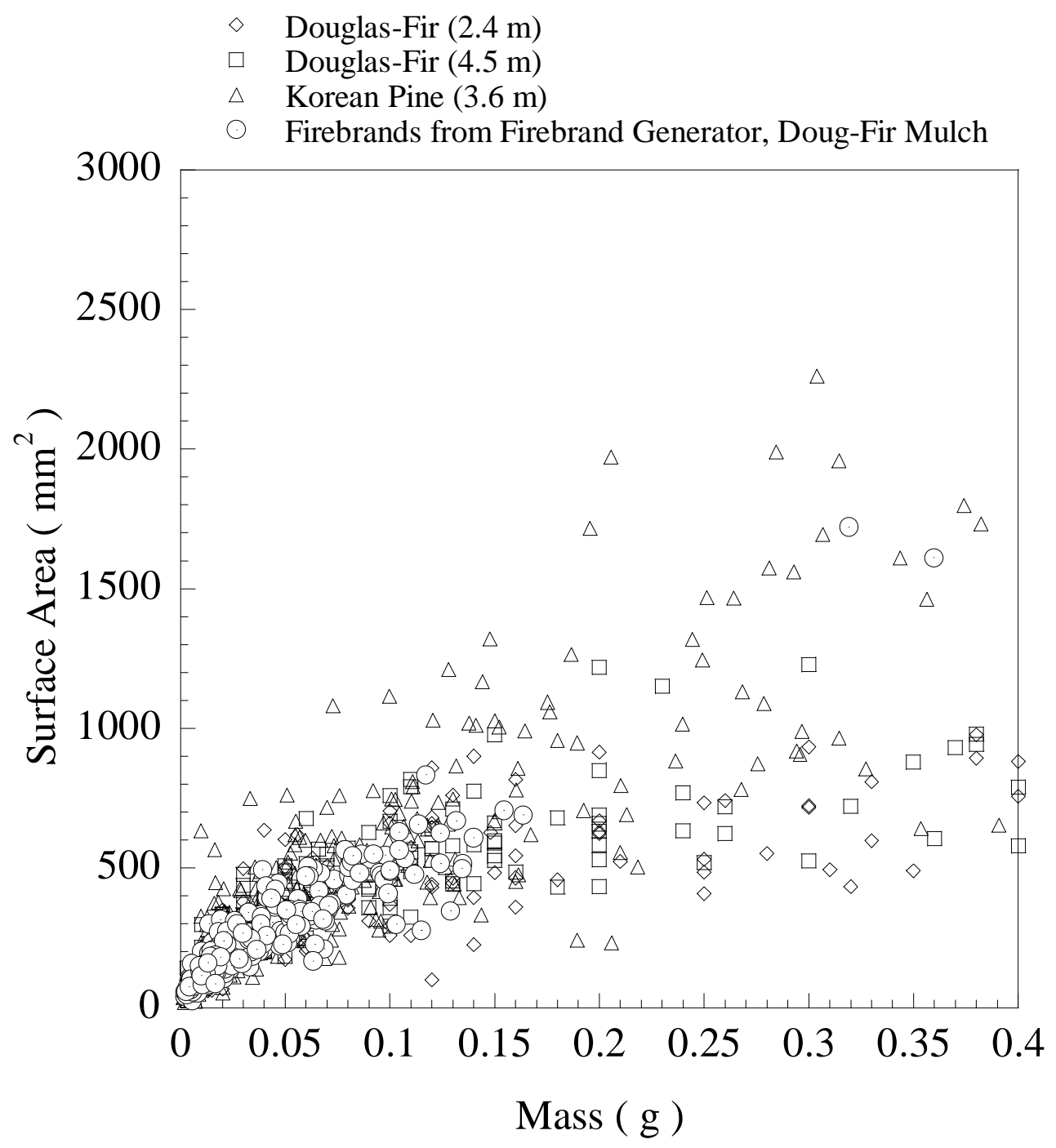

Fig. 3. Firebrands produced from Firebrand Generator compared to firebrands collected from burning trees. The dimensions assigned to the trees correspond to crown heights.

\section{BASE LAYER- ORIENTED STRAND BOARD (OSB) EXPERIMENTS}

Consequently, the first series of experiments conducted at the FRWTF consisted of full scale sections of base layer roofing materials; OSB was used. In these experiments, a full scale section $(122 \mathrm{~cm}$ by $122 \mathrm{~cm}$ by $9 \mathrm{~mm}$ thick) of a roof was installed inside the custom mounting assembly (shown in Fig. 4). The pitch 
of the full scale section was fixed at $35^{\circ}$, and similar to the small scale experiments described above, the angle was varied from $60^{\circ}$ to $135^{\circ}$. To be able to control the moisture content of full scale sections, the experiments were designed in a modular fashion. Specifically, the $122 \mathrm{~cm}$ by $122 \mathrm{~cm}$ full section was comprised of four separate OSB pieces. This allowed each section to be oven dried and once dried, simply reassembled inside the custom mounting frame. The OSB was taken from the same batch of OSB purchased for the small scale experiments.

Figure 5 displays a sequence of images obtained from the present experiments. Similar to the small scale experiments, ignition events were not observed for moist samples; ignition only occurred when the OSB samples were oven dried. This can be explained by the higher heating value and thermal inertial of the samples. The moisture embedded in the samples reduces the thermal efficiency since the heating and gasification of water consume additional energy. Consequently this will result in the high value of heat of gasification, reducing the net heat flux to the fuel bed. The moisture content is also known to affect the density of the fuel bed material, the thermal conductivity, and the specific heat, and thus the thermal inertia. A high thermal inertia value for a wet fuel bed increases a thermal resistance to changes in temperature, reducing ignitibility.

At an angle of $60^{\circ}$, the firebrands were observed to collect inside the channel of the OSB crevice. The dynamics of the ignition process were repeatable and very interesting to observe. The firebrands that collected in the crevice produced smoldering ignition where they landed, eventually resulting in several holes in the OSB. The OSB continued to smolder intensely near the locations where the firebrands landed. Eventually a transition to flaming ignition was observed on the back side of the OSB. As the angle was increased to $90^{\circ}$, similar behavior was observed where the firebrands that collected initiated intense smoldering. Eventually, holes were formed at these locations in an identical manner to the $60^{\circ}$. While smoldering ignition was observed, it was not possible for a transition to flaming to occur. As the angle was increased to $135^{\circ}$, ignition was no longer possible. The wind tunnel flow was set to $7 \mathrm{~m} / \mathrm{s}$ in these experiments; this corresponded to a $4.8 \mathrm{~m} / \mathrm{s}$ velocity at the center of the OSB crevice.
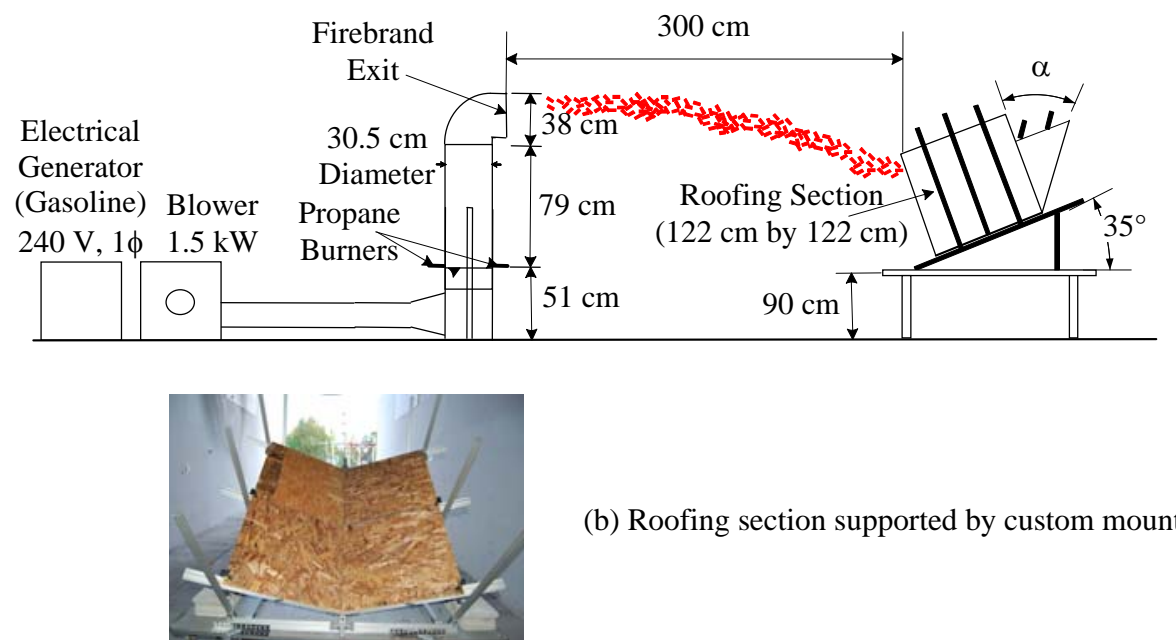

(b) Roofing section supported by custom mounting assembly

Fig. 4. Firebrands deposited onto full scale roofing sections; (a) side view (b) front view-detail.

From the small scale experiments using only four deposited glowing firebrands, it was not possible to ignite bare OSB at angles of $135^{\circ}$. With regard to the full scale experiments, the flux of firebrands was several orders of magnitudes higher as compared to the small scale experiments, but it was still not possible to ignite bare OSB at an angle of $135^{\circ}$.

The arrangement of deposited firebrands greatly affected the net heat flux to the OSB surface. At a tighter angle, it is easier for the glowing firebrands to stack together. The firebrands that stack together at the tighter angle will irradiate more heat flux on a given area, energizing the area in contact with firebrands more effectively. Both the present full scale experiments as well as the small scale experiments described indicate that at angles of $135^{\circ}$, firebrands are not able to accumulate and ignite OSB. 


\section{ROOFING ASSEMBLY EXPERIMENTS -VALLEYS}

After the base layer OSB experiments were completed, it was desired to construct roofing sections of the same size but consider the influence of adding tar paper and shingles on top of the bare OSB. This type of roofing construction is very common in the USA. It is important to realize that bare OSB is not used as the surface material in roofing but roofs in a state of ill repair may easily have base layer materials such as OSB exposed to the elements. The custom mounting assembly allowed for the construction of valleys (angled) roofs. Since firebrands were observed to easily ignite the base sheathing material (OSB) at angles of $60^{\circ}$ and $90^{\circ}$, roof valleys were constructed using the same angles.

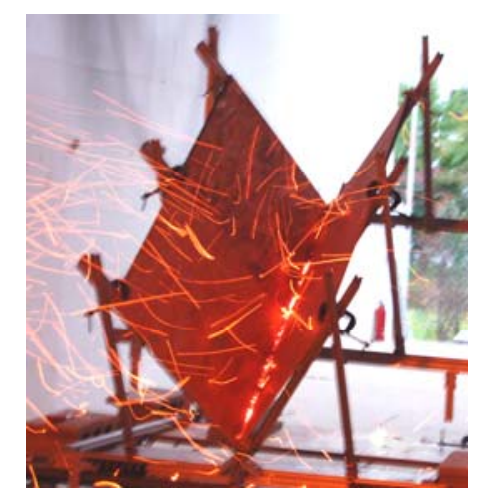

(a)

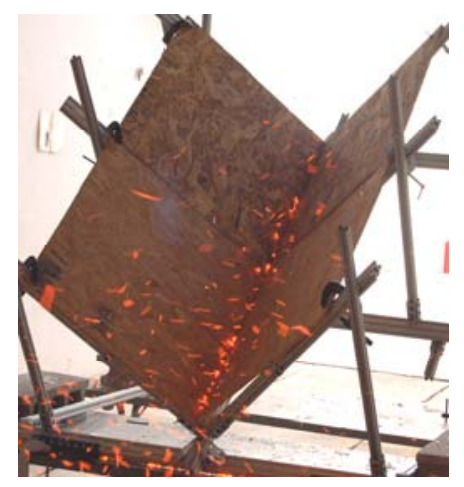

(b)

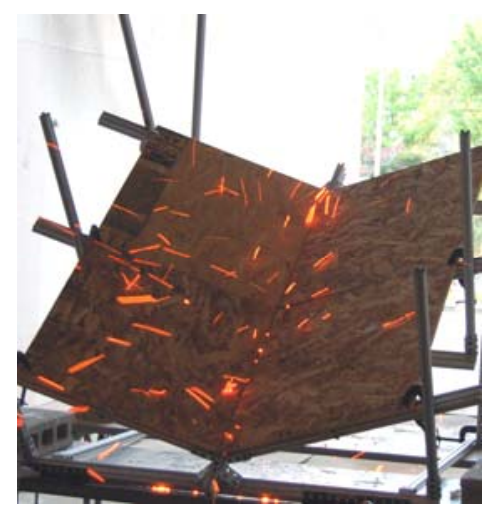

(c)

Fig. 5. Bare OSB full scale sections used for testing. (a) Angle of $60^{\circ}$; smoldering ignition observed (b) Angle of $90^{\circ}$; smoldering ignition observed (c) Angle of $135^{\circ}$; no ignition observed. 
Figure 6 displays the results obtained at angle of $90^{\circ}$. At $60^{\circ}$ and $90^{\circ}$, several firebrands were observed to become trapped along the crevice of two sections and along the seams of the shingles. However, no ignition events were observed. The firebrands were only capable of melting the asphalt shingles. As the angle was spread further, fewer firebrands were observed to become trapped in seam of the two sections, in similar manner to base OSB tests described in Fig. 5.

In these experiments, the shingles used were new and care was taken to seal each row of shingles. For older roofs found in practice, aged shingles would not be expected to perform as well as new shingles since they would not be expected to be sealed well along the seams due the weathering process. In addition, the present experiments did not consider the influence of pre-heated shingles. In actual fires, the shingles are not expected to be cold $\left(20^{\circ} \mathrm{C}\right)$ since they will, at minimum, be pre-heated by solar radiation. In light of these differences, the present results clearly indicate that firebrands can melt new, cold, asphalt shingles. Once the firebrands penetrate the shingles, the base layer material (OSB) was found to be ignited rather easily (see Fig. 5).

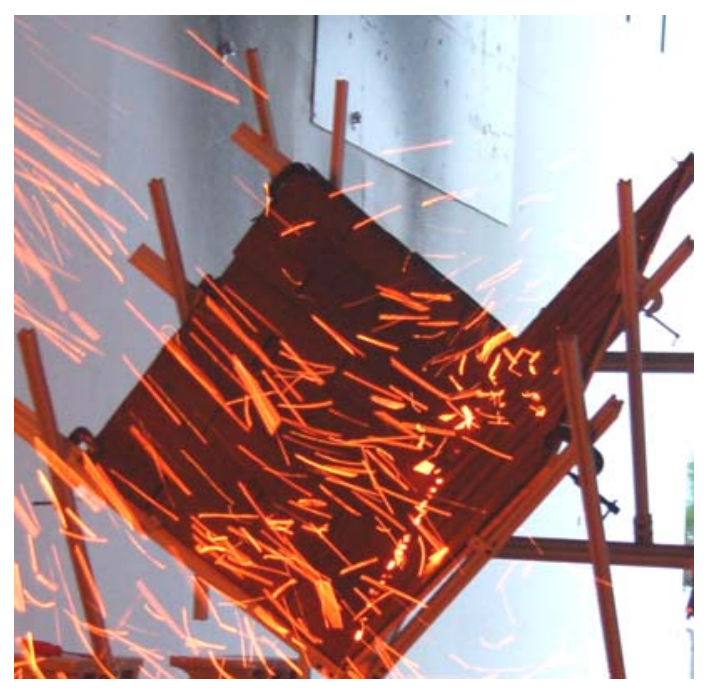

Fig. 6. OSB base layer, tar paper, and asphalt shingles; Angle of $90^{\circ}$-no ignition observed.

\section{ROOFING ASSEMBLY EXPERIMENTS - GUTTERS ATTACHED}

It is believed that pine needles in the gutters of homes are susceptible to ignition by firebrand showers. Having developed the unique Firebrand Generator, it was possible to investigate this. The custom mounting assembly was configured to accommodate a flat roof section. The pitch was set to $35^{\circ}$ and a gutter was attached to the front. The gutter was constructed of polyvinyl chloride (PVC); a gutter material found in new home construction. As in the roof valley experiments described above, OSB was used as the base layer; tar paper and shingles were then applied. Dried pine needles and leaves were used and placed inside the gutter.

Figure 7 displays typical results obtained from the experiments. The firebrands that were deposited inside the gutter produced smoldering ignition inside the gutter. The smoldering intensified and ultimately this transitioned to flaming ignition. The asphalt shingles were observed to melt once exposed to the intense flaming that occurred inside the gutter. The flames, however, did not spread up the roof section. While the flames did not spread upwards along the roof, these images are very important to disseminate to home owners in WUI areas since they clearly show the dangers of simply not cleaning gutters. The influence of pre-heated shingles as well as aged shingles was not addressed. 


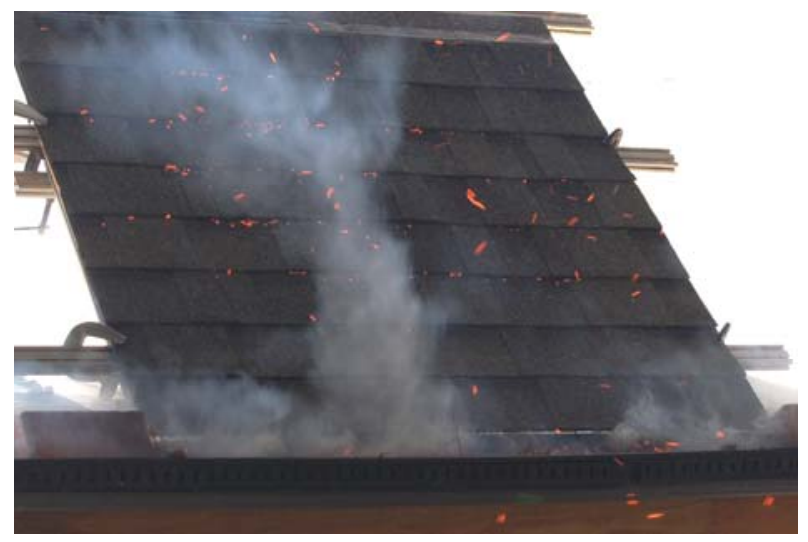

(a)

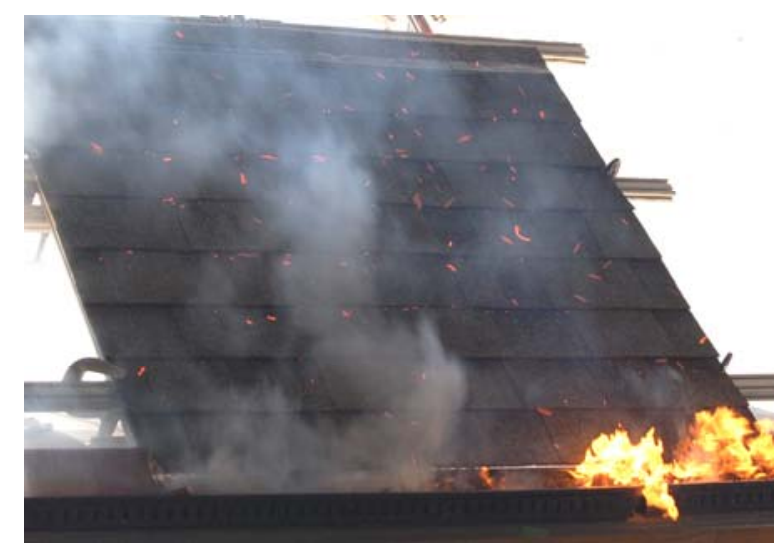

(b)

Fig. 7. Section of full scale roof assembly. (a) Smoldering ignition of needles/leaves inside gutter (b) Transition to flaming ignition.

\section{SUMMARY}

The vulnerability of roofing materials to firebrand attack was ascertained using fluxes of firebrands produced using the Firebrand Generator. The experiments were performed at the Fire Research Wind Tunnel Facility (FRWTF) at the Building Research Institute (BRI) in Tsukuba, Japan. A custom mounting assembly was constructed to support full scale sections of common roofing materials inside the wind tunnel. The full scale sections constructed for testing included roofing assemblies (base layer material, tar paper, and shingles) as well as only the base layer roofing material, such as oriented strand board (OSB). The custom mounting assembly allowed for the construction of flat roof subsections as well as the construction of valleys (angled) roofs.

For ignition testing of roofing base layer materials (OSB), at an angle of $60^{\circ}$, the firebrands were observed to collect inside the channel of the OSB crevice. The firebrands that collected in the crevice produced smoldering ignition where they landed, eventually resulting in several holes in the OSB. The OSB continued to smolder intensely near the locations where the firebrands landed. Eventually a transition to flaming ignition was observed on the back side of the OSB. As the angle was increased to $90^{\circ}$, similar behavior was observed where the firebrands that collected initiated intense smoldering. Eventually, holes were formed at these locations in an identical manner to the $60^{\circ}$. While smoldering ignition was observed, it was not possible for a transition to flaming to occur. As the angle was increased to $135^{\circ}$, ignition was no longer possible. These results were similar to small scale ignition testing of OSB. It is important to realize 
that bare OSB is not used as the surface material in roofing but roofs in a state of ill repair may easily have base layer materials such as OSB exposed to the elements.

With regard to ignition testing of roofing valleys (OSB, tar paper, and asphalt shingles), at $60^{\circ}$ and $90^{\circ}$, several firebrands were observed to become trapped along the channel of two sections and along the seams of the shingles. However, no ignition events were observed. The firebrands were only capable of melting the asphalt shingles. As the angle was spread further, fewer firebrands were observed to become trapped in seam of the two sections, in similar manner to base layer OSB tests described. These tests did not consider the influence of aged shingles or pre-heated shingles. The present results clearly indicate that firebrands can melt asphalt shingles. Once the firebrands penetrate the shingles, the base layer (OSB) was found to be ignited rather easily.

For roofing assemblies with gutters attached, the firebrands that were deposited inside the gutter produced smoldering ignition inside the gutter. The smoldering intensified and ultimately this transitioned to flaming ignition. The asphalt shingles were observed to melt once exposed to the intense flaming that occurred inside the gutter. The flames, however, did not spread up the roof section. While the flames did not spread upwards along the roof, these images are very important to disseminate to home owners in WUI areas since they clearly show the dangers of simply not cleaning gutters.

The present experiments have clearly shown the utility of the Firebrand Generator. It is desired to use these results to provide scientific guidance for enhanced building standards in the USA and Japan.

\section{ACKNOWLEDGMENTS}

The work conducted by BFRL-NIST staff at BRI was possible through a Memorandum of Understanding (MOU) in place between BFRL-NIST and BRI. Mr. Syuuji Nanno (BRI Guest Researcher, under the supervision of Dr. Ichiro Hagiwara of BRI) completed some of the analysis for the firebrand mass and size distributions; his able help in this regard is appreciated. Mr. Ethan Foote of the California Department of Forestry and Fire Protection (CALFIRE) is acknowledged for helpful discussions.

\section{REFERENCES}

[1] Government Accountability Office, Technology Assessment: Protecting Structures and Improving Communications During Wildland Fires, GAO-05-380, 2005.

[2] F. Albini, Spot Fire Distances From Burning Trees - A Predictive Model, USDA Forest Service General Technical Report INT-56, Missoula, MT, 1979.

[3] F. Albini, Combustion Science and Technology 32 (1983) 277-288. doi: 10.1080/00102208308923662.

[4] A. Muraszew, J.F. Fedele, Statistical Model for Spot Fire Spread, The Aerospace Corporation Report No. ATR-77758801, Los Angeles, CA, 1976.

[5] C.S. Tarifa, P.P. del Notario, F.G. Moreno, Proceedings of the Combustion Institute 10 (1965) 1021- 1037.

[6] C.S. Tarifa, P.P. del Notario, F.G. Moreno, Transport and Combustion of Fire Brands.' Instituto Nacional de Tecnica Aerospacial "Esteban Terradas", Final Report of Grants FG-SP 114 and FG-SP-146, Vol. 2. (Madrid, Spain) 1967.

[7] S.D. Tse, A.C. Fernandez-Pello, Fire Safety Journal 30 (1998) 333-356. doi: 10.1016/S0379 7112(97)00050-7

[8] R. Anthenian, S.D. Tse, A.C. Fernandez-Pello, Fire Safety Journal 41 (2006) 349-363. doi: 10.1016/j.firesaf.2006.01.005 
[9] J.P. Woycheese, Brand Lofting and Propagation for Large-Scale Fires, Ph.D. Thesis, University of California, Berkeley, 2000.

[10] K. Himoto, T. Tanaka, Fire Safety Science 8 (2005) 433-444.

[11] I.K. Knight, Fire Technology 37 (2001) 87-100. doi: 10.1023/A:1011605719943.

[12] S.L. Manzello, J.R. Shields, J.C. Yang, Y. Hayashi, and D. Nii, On the Use of a Firebrand Generator to Investigate the Ignition of Structures in WUI Fires, Proceedings of the $11^{\text {th }}$ International Conference on Fire Science and Engineering (INTERLFAM), Interscience Communications, London, 2007, pp. 861-872.

[13] Standard Test Methods for Fire Tests of Roof Coverings, ASTM E108, American Society for Testing and Materials, West Conshohocken, PA.

[14] S.L. Manzello, J.R. Shields, T.G. Cleary, A. Maranghides, W.E. Mell, J.C. Yang, Y. Hayashi, D. Nii, T. Kurita, Fire Safety Journal (2008)in press. doi: 10.1016/j.firesaf.2007.10.001.

[15] S.L. Manzello, A. Maranghides, W.E. Mell, International Journal of Wildland Fire 16 (2007) 458-462. doi: 10.1071/WF06079.

[16] S.L. Manzello, J.R. Shields, A. Maranghides, W.E. Mell, Y. Hayashi, D. Nii (2008)Fire and Materials (2008), in press. doi: 10.1002/fam.977.

[17] R.S. White, G. Winandy, Fire Performance of Oriented Strand Board (OSB), Seventeenth Annual BCC Conference on Fire Retardancy, p.297-390, 2006.

[18] S.L. Manzello, S. Park, T.G. Cleary. J.C. Yang, Fire Safety Journal (2008) in review.

[19] S.L. Manzello, T.G. Cleary, J.R. Shields, J.C. Yang, Fire and Materials 30 (2006) 77-87. doi: 10.1002/fam.901. 